\title{
Liver Cancer pN0 TNM Finding v7
}

National Cancer Institute

\section{Source}

National Cancer Institute. Liver Cancer pNO TNM Finding v7. NCI Thesaurus. Code C90166.

Liver cancer with no regional lymph node metastasis. (from AJCC 7th Ed.) 